\title{
In-office and out-of-office blood pressure measurement
}

\author{
Kei Asayama $\mathbb{D}^{1,2,3} \cdot$ Takayoshi Ohkubo $\mathbb{D}^{1,3} \cdot$ Yutaka Imai ${ }^{3}$
}

Received: 11 September 2020 / Revised: 10 November 2020 / Accepted: 15 January 2021

(c) The Author(s), under exclusive licence to Springer Nature Limited 2021

\begin{abstract}
Accurate blood pressure measurement is the key procedure for the diagnosis and treatment of hypertension. In-office and outof-office blood pressure measurements both have advantages and weak points, and multifaceted blood pressure information in individuals should be appropriately obtained and assessed. Validation of blood pressure measurement devices has long been an important issue, and several consortiums have emerged to try address it. Clinical guidelines should meet the demands of the region in which they are applied, and out-of-office measurements have been widely stated and recommended in the recently published guidelines worldwide. Appropriate assessment of blood pressure should be performed routinely in order to provide timely and accurate evidence regarding hypertension under any situation, including an unexpected pandemic.
\end{abstract}

\section{Introduction}

Accurate blood pressure measurement is the cornerstone of the diagnosis and treatment of hypertension. Contrary to expectation, the most preferable method cannot be settled solely because it greatly depends on the condition of the patient, the environment of the measurement space, and the measurement device. Furthermore, a combination of blood pressure information as well as regular, continual measurement of blood pressure is also fundamental for appropriate management of blood pressure. In this review, we provide an overview of the current topics on blood pressure measurement, including automated office blood pressure (AOBP) and validation of blood pressure measurement devices, in relation to the recommendations in the most recent guidelines [1-4] on hypertension.

Kei Asayama

kei@asayama.org

1 Department of Hygiene and Public Health, Teikyo University School of Medicine, Tokyo, Japan

2 Studies Coordinating Centre, Research Unit Hypertension and Cardiovascular Epidemiology, KU Leuven Department of Cardiovascular Sciences, University of Leuven, Leuven, Belgium

3 Tohoku Institute for Management of Blood Pressure, Sendai, Japan

\section{Conventional "in-office" blood pressure}

Conventional blood pressure, which is measured at an office or in a screening setting by a sphygmomanometer, has been used as the gold standard of blood pressure measurement techniques regardless of the guidelines based on cumulative evidence and common use in clinical practice. Although variations in measurement conditions still exist, office blood pressure should be measured after a few minutes [1] - 3 [4], 5 [2], or $>5$ [3] min—of rest, twice [1, 3] or three times $[2,4]$ and then these values should be averaged with special conditions, as summarized in Table 1.

AOBP was initially defined as office blood pressure measured by an automated device for multiple readings (three times or more [5]), recorded automatically with the patient under rest in an undisturbed quiet room in the absence of an observer [5, 6]. Five minutes of rest in the unattended setting before AOBP measurement has been further used in many recent studies (Table 1) [7-9]. Stults et al. raised concern about inhabitation of AOBP utilization in real-world settings [10]; the AOBP including antecedent rest time requires $>10$ min per person, which includes a few minutes for preparation and clean up. The Hypertension Canada 2018 Guidelines stated that AOBP may be performed with no special period of rest [11]. However, as we discussed in detail elsewhere [8], this statement can be applied almost exclusively for measurement using BpTRU (BpTRU Medical Devices, Coquitlam, Canada; the company ceased operations in 2017) which usually performs six consecutive readings and averages two to six readings. The discard of the first reading serves as the antecedent rest 
Table 1 Office blood pressure measurement conditions using an automated device.

\begin{tabular}{|c|c|c|c|c|c|}
\hline Items & $\begin{array}{l}\text { AOBP with } \\
\text { antecedent rest time }\end{array}$ & ACC/AHA 2017 [3] & ESC/ESH 2018 [2] & JSH 2019 [1] & 2020 ISH [4] \\
\hline \multicolumn{6}{|c|}{ Before the measurement } \\
\hline Rest period & $5 \mathrm{~min}$ & $>5 \min$ & $5 \mathrm{~min}$ & A few min & $3-5 \min$ \\
\hline Medical staff & Absent & N/A (present) & N/A (present) & N/A (present) & N/A (present) \\
\hline $\begin{array}{l}\text { Inspection the } \\
\text { measurement }\end{array}$ & $\begin{array}{l}\text { No; instructed } \\
\text { before the start, and } \\
\text { left alone }\end{array}$ & All & All & All & All \\
\hline \multicolumn{6}{|c|}{ During the measurement } \\
\hline Interval & $1 \mathrm{~min}$ & $1-2 \mathrm{~min}$ & $1-2 \min$ & $1-2 \min$ & $1 \mathrm{~min}$ \\
\hline Medical staff & Absent & N/A (present) & N/A (present) & N/A (present) & N/A (present) \\
\hline Measurement times & $\geq 3$ & $\geq 2$ & $\begin{array}{l}3 \text {; additionally } 1 \text { when the } \\
\text { first and second readings } \\
\text { differ by }>10 \mathrm{mmHg}\end{array}$ & $\begin{array}{l}\geq 2 ; 3 \text { when a person is a } \\
\text { child, or has arrhythmia } \\
\text { or other conditions }\end{array}$ & $\begin{array}{l}3 \text {, or } 1 \text { if the first } \\
\text { reading is }<130 / \\
85 \mathrm{mmHg}\end{array}$ \\
\hline Average the readings & All & $\begin{array}{l}\geq 2 \text { readings obtained } \\
\text { on } \geq 2 \text { occasions }\end{array}$ & The last 2 readings & $\begin{array}{l}2 \text { readings with } \leq 5 \mathrm{mmHg} \\
\text { difference }\end{array}$ & The last 2 readings \\
\hline
\end{tabular}

Conditions are applicable for measurements using an automated device. The measurement condition of automated office blood pressure (AOBP) was expanded from the original definitions to include $5 \mathrm{~min}$ antecedent time and average all the three measurements, which was used in the recent studies [7-9]. JSH 2019, ACC/AHA 2017, ESC/ESH 2018, and 2020 ISH denote the Japanese Society of Hypertension Guidelines for the Management of Hypertension (JSH 2019), the 2017 American College of Cardiology/American Heart Association Guidelines, the 2018 European Society of Cardiology/European Society of Hypertension Guidelines, and the 2020 International Society of Hypertension Global Hypertension Practice Guidelines, respectively.

time, and it is fair to prepare a certain rest time before the first measurement -5 min would be acceptable regarding conventional measurement-when we average all the measurement values. Whereas, a conventional office blood pressure measurement also requires more than a few minutes' antecedent rest when faithfully based on recent guidelines [1-4]. Although the antecedent rest time might not be mandatory when systolic blood pressure level is $<130 \mathrm{mmHg}$ [12], the amendment of the measurement protocol according to the estimated values makes it difficult to evaluate and compare the measurements among individuals. Furthermore, the consumption of office space in addition to long measurement time reduces the feasibility of AOBP [8]. We need at least one extra separate room with a person in charge to manage the AOBP measurement and the cost of the measurement is generally not reimbursed [8].

Recent studies reported that average levels of AOBP were similar to the 24-h ambulatory blood pressure in a population $[9,13]$. However, we cannot conclude that AOBP can alter the out-of-office measurement because the variation in differences by individuals should not be ignored. Our research group recently reported that there was a marked variation in individuals between self-measured home blood pressure and AOBP values, while average levels are almost identical, as systolic blood pressure difference was $0.9 \mathrm{mmHg}$, with a $95 \%$ agreement limit of -34.0 to $35.8 \mathrm{mmHg}$ (home blood pressure was measured in the morning; adjusted correlation coefficients, 0.14 ; $95 \%$ confidence intervals (CI), 0.03-0.25) [8]. These low correlations and wide range of difference indicate that we cannot estimate out-of-office blood pressure values by AOBP measurements in individuals and vice versa, and AOBP cannot be used as an alternative to home blood pressure [8].

Besides the white-coat observer effect by the presence of medical staff [6], AOBP measurement is performed at a clinic or in a screening setting where participants cannot be fully relaxed like at their own home. Such a clinic effect still affects in-office readings even based on AOBP [8]. Home blood pressure has no clinic effect regardless of selfmeasurement or observer measurement; however, participants can be affected by the observer effect during the latter observer measurement of home blood pressure. The environmental condition can be cross-classified as shown in Fig. 1 [14]. Meanwhile, blood pressure might be increased by arousal or by arm-cuff inflation [15]. In this respect, nighttime ambulatory blood pressure values during sleep, when measurements are free from arousal and alerting reactions, would have great prognostic ability for cardiovascular complications [16]. Much still remains to be done for the assessment of the wide variety of blood pressure conditions.

\section{Ambulatory and home blood pressure}

Self-measured home blood pressure and ambulatory blood pressure monitoring are categorized as out-of-office blood pressure, and they have more prognostic ability than conventional in-office blood pressure [16-18]. Beyond its 
Fig. 1 Cross-classification of blood pressure measurement conditions and effects. Outof-office blood pressure measurements are presented in the left panels $(\mathbf{A}, \mathbf{C})$, with inoffice measurements in the right panels $(\mathbf{B}, \mathbf{D})$. During the measurements, medical staff are in attendance $(\mathbf{A}, \mathbf{B})$ during home visit/home healthcare/ surveillance $(\mathbf{A})$ or not in attendance (C, D). Out-ofoffice blood pressure includes, but is not limited to, home measurements. Ambulatory blood pressure monitoring (overlaid domain) is performed at various locations, mostly out-of-office settings. For automated office blood pressure (D), medical staff are not in attendance but supervise the measurement procedure. Reproduced from Asayama et al. [14].
Out-of-Office

In-Office

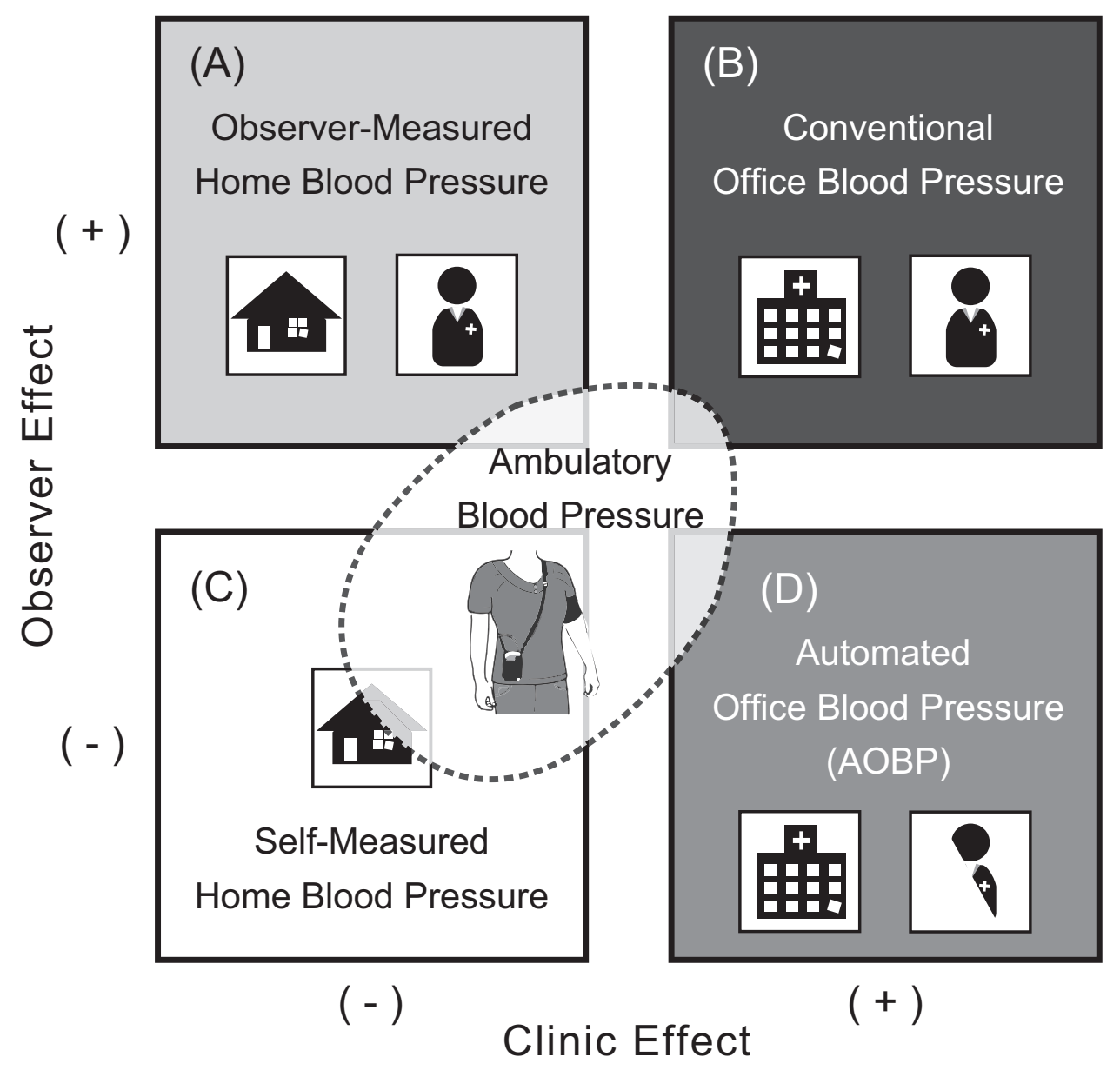

greater predictive power, home blood pressure can substantially refine conventional in-office blood pressure-based risk stratification, particularly among those whose in-office blood pressure levels are assumed to carry no or tiny increased cardiovascular risk [19]; the utility of risk stratification was also reported based on ambulatory blood pressure values [20]. Our research group recently performed participant-level meta-analysis based on 11,135 adults from Europe, Asia, and South America who measured 24-h ambulatory blood pressure [16]. Per $20 \mathrm{mmHg}$ nighttime systolic blood pressure increments, the multivariableadjusted hazard ratio for total mortality was $1.23(95 \%$ CI, 1.17-1.28) and for cardiovascular events was $1.36(95 \%$ CI, 1.30-1.43). Results were essentially similar when 24-h ambulatory measurements were assessed. Furthermore, even after adjustment for any of the other systolic blood pressure indexes, e.g., daytime blood pressure, or in-office conventional blood pressure or AOBP, both 24-h and nighttime systolic blood pressures were significantly associated with mortality and composite cardiovascular outcome. Although the usefulness of in-office blood pressure should not be underestimated with respect to identifying white-coat and masked hypertension [19, 21], the usefulness of out-of-office blood pressure as a single source of information would be unwavering. Meanwhile, it is fair to note that we defined AOBP in that analysis [16] as the mean of the ambulatory recordings during the first recording hour because the monitors in that period were applied in a medical environment. The measurement did not follow the aforementioned AOBP criteria, and there is room for investigating whether ambulatory blood pressure is superior to AOBP under the defined measurement condition $[5,6]$.

Based on measurements under well-defined conditions, we reported the current status of self-measured home blood pressure among Japanese five cohorts [22]. According to the recent Japanese guidelines (JSH 2019) [1], participants in the Modern DAtabase on Self-measured home blood pressure (MDAS) measured morning home blood pressure within $1 \mathrm{~h}$ of waking before breakfast and taking antihypertensive medication if any, after urination, and after a few minutes of rest in a sitting position. They measured evening home blood pressure just before going to bed after a few minutes of rest in a sitting 


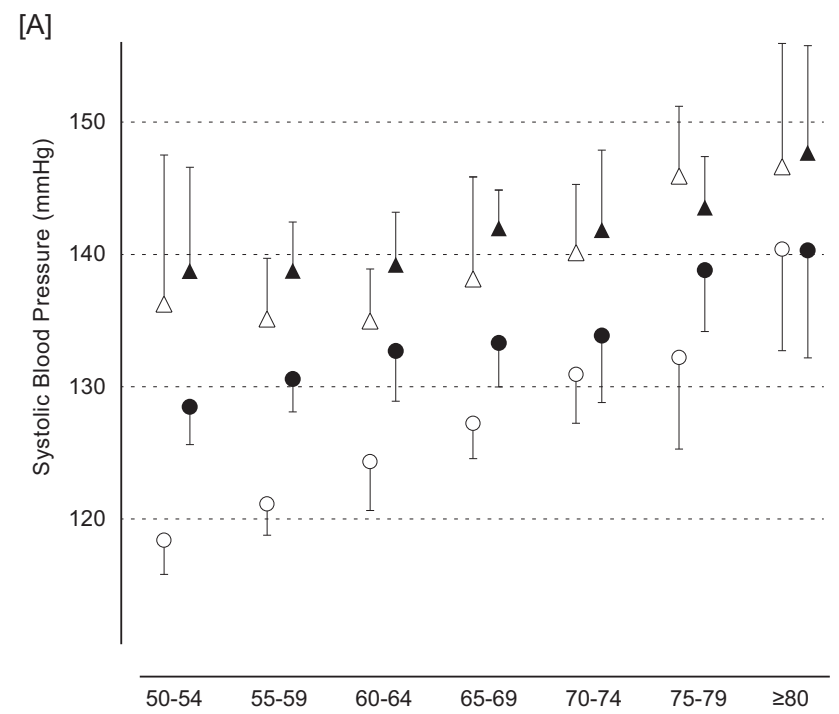

$[\mathrm{C}]$

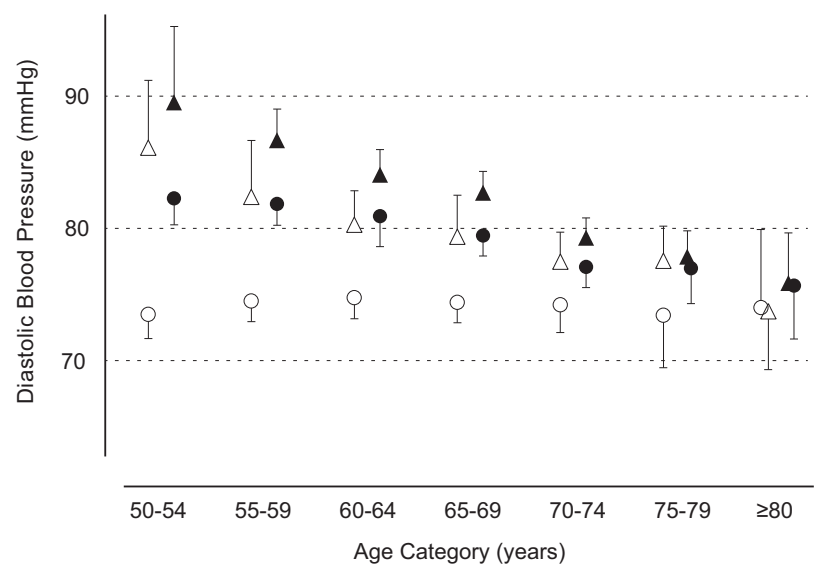

Fig. 2 The self-measured home blood pressure among Japanese five cohorts in each 5-year age category. The mean systolic $(\mathbf{A}, \mathbf{B})$ and diastolic $(\mathbf{C}, \mathbf{D})$ home blood pressure measured in the morning $(\mathbf{A}, \mathbf{C})$ and evening (B, D). Error bars indicate one-sided 95\% confidence intervals. The horizontal auxiliary lines, which represent blood pressure level, are aligned in height on the adjacent panels. Heterogeneity tests among the

position. The measurement period was 2001-2018, and they used two home blood pressure measurement devices made using the same measurement technology (HEM-705IT and HEM-7080IC, Omron Healthcare Co. Ltd, Kyoto, Japan) except the earlier periods of Ohasama (2001-2017) in which another validated device from the same manufacturer (HEM-747IC-N) was used. Aggregate summary data per classified cell of sex, age group in 5-year intervals, and antihypertensive drug treatment were collected and integrated, and mean blood pressure values in each cell were calculated by a meta-analysis approach. Morning home blood pressure was consistently higher than evening blood pressure regardless of age group, sex, and antihypertensive treatment (Fig. 2), and that among participants receiving antihypertensive medication was higher than those
[B]

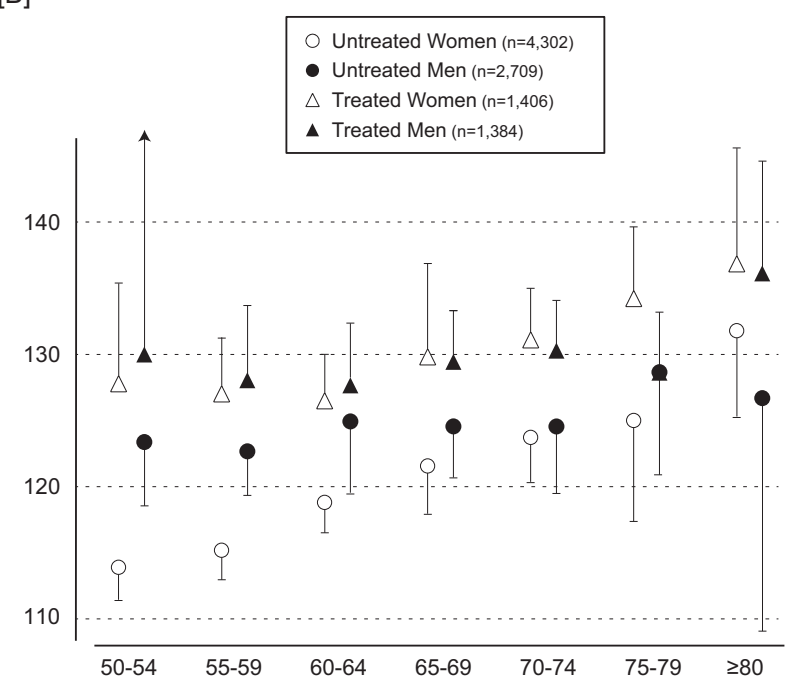

[D]

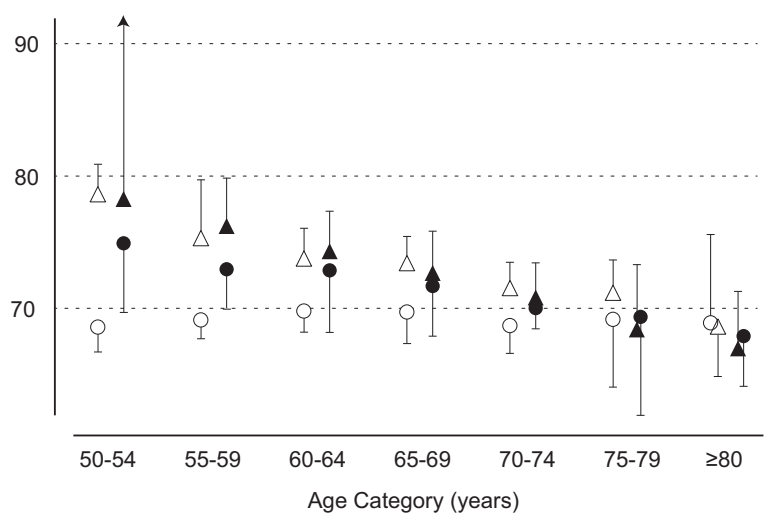

cohorts were not significant (corrected $P \geq 0.063$ ), with the exception of treated men aged 70-74 years (corrected $P=0.0030$ ) in the morning measurement and of untreated men aged 60-64 years (corrected $P=$ 0.0091 ) and 75-79 years (corrected $P=0.033$ ). Reproduced from Asayama et al. [22].

without medication. The average diastolic blood pressure was almost identical among those $\geq 80$ years of age, regardless of sex and antihypertensive treatment status, in both the morning (73.7-75.8 $\mathrm{mmHg}$ ) and evening $(67.1-68.9 \mathrm{mmHg})$ measurements. Home measurement values were grossly homogenous among the study population by heterogeneity tests, suggesting sufficient representativeness of these data on recent home blood pressure levels among Japanese.

\section{Measurement devices}

As marketed medical tools, manufacturers of the blood pressure measurement devices have to follow domestic 
standards and obtain approval from governmental organizations in each country [23]. In the majority of cases, however, blood pressure is measured under diverse clinical settings and such government agencies have little responsibility for the validation of accuracy in each setting. Validation studies are therefore provided according to the measurement settings, including age group, anthropometric condition, and with consideration of those having a special condition such as pregnancy, children, or treated by hemodialysis. For example, the MDAS coworkers performed a validation study of their device for a population aged around 85 years old; this resulted in the first publication for guaranteeing a home blood pressure measurement device for oldest-olds [24]. The Association for the Advancement of Medical Instrumentation (AAMI) and American National Standards Institute (ANSI) revised the ANSI/AAMI standard to adopt International Organization for Standardization (ISO) standards (ISO 81060-2:2013) [25], and the European Society of Hypertension (ESH) [26] recently followed the updated ISO standards (ISO 810602:2019) [27]. It should be noted that the ISO standards have been published under the full responsibility of the ISO committees, although these recent standards are sometimes called by different name in different organizations which contributed to the standards, e.g., ANSI/AAMI/ISO [28] or AAMI/ESH/ISO [26].

According to a recent report, $<15 \%$ of blood pressure measurement devices have undergone independent validation testing among $>3300$ devices worldwide from $>450$ manufacturers [29]. In the online marketplace available from Australia on December 2018, only $18.3 \%$ of the 278 unique upper arm-cuff home blood pressure measurement devices for sale had passed international validation protocols, and the prevalence of validated wristband-wearable devices among 532 unique ones on the market was zero [30]. Several consortiums have tried addressing the blood pressure validation issues. The Accuracy in Measurement of Blood Pressure (AIM-BP) Collaborative is focused on advocating for and implementing optimal blood pressure measurement practice globally by complimentary existing efforts [31]. The activity of AIM-BP is in connection with the Lancet Commission on Hypertension Group [32], the World Hypertension League, and related organizations [33], and major objectives of the Collaborative include "host a webpage on the World Hypertension League website that summarizes critical information and resources" [31]. Such summarization of blood pressure measurement information has been conducted by several organizations, e.g., dabl Educational Trust [34] and Medaval [35]. Despite the great efforts, people have been facing difficulty providing information continuously as dabl Educational Trust is no longer actively updated [29], and to make and update the summary under a fair and accurate fashion is also tough partly because interpretation of publications regarding validation of blood pressure device can differ. In the Science and Technology for Regional Innovation and Development in Europe BP initiative which was founded in 2018 by international experts in blood pressure measurement, the board members independently review publications on blood pressure variability based on the concurrent knowledge and advancement of validation procedures, and they judge whether the device is acceptable for defined measurement situation such as in the general population, children, etc. [36]. In contrast, our group organized a working group within the Japanese Society of Hypertension (JSH), and, in 2016, started to collect information on blood pressure measurement devices marketed in Japan (http://www.jpnsh. jp/com_ac_wg1.html). In this listing updated annually, we refrain from scoring the devices; instead, we ask the device manufacturers via several public consortiums to provide related data in detail, and we disseminate the information without essentially processing it. Although this activity is mainly targeted toward Japanese, this local activity is also compatible with the global practice in AIM-BP [31].

\section{Out-of-office blood pressure in guidelines}

In the 2017 ACC/AHA Guidelines, out-of-office blood pressure measurements were "recommend to confirm the diagnosis of hypertension and for titration of blood pressure-lowering medication, in conjunction with telehealth counseling or clinical interventions" [3]. Similarly, wider use of out-of-office blood pressure measurement is "an option to confirm the diagnosis of hypertension" by the 2018 ESC/ESH Guidelines [2]. As Jones [37] summarized, diagnosis based on in-office blood pressure is still an essential blood pressure management decision in the US and European guidelines. However, in the 2018 ESC/ESH Guidelines, out-of-office BP, particularly home blood pressure, is recognized as a tool for detection of white-coat and masked hypertension as well as for monitoring blood pressure control [2]. AOBP theoretically enhances the inoffice blood pressure measurement condition [37] if practitioners are able to prepare the environment of AOBP.

A unique vision of the JSH regarding out-of-office blood pressure is worth introducing. Out-of-office blood pressure is "often considered to have clinical values comparable to, or greater than, that of office blood pressure" [1]. The difference in the nature of blood pressure information is summarized in Table 2. Furthermore, the home blood pressurebased six-graded classification is provided based on a recent outcome-driven meta-analysis [38]. Although there is currently no randomized trial to guarantee the classification based on home blood pressure, the JSH 2019 Guidelines certainly met the expectations in the applied country. Home 
Table 2 Characteristics of blood pressure information.

\begin{tabular}{|c|c|c|c|}
\hline Item & $\begin{array}{l}\text { Office blood } \\
\text { pressure }\end{array}$ & $\begin{array}{l}\text { Home blood } \\
\text { pressure }\end{array}$ & $\begin{array}{l}\text { Ambulatory blood } \\
\text { pressure }\end{array}$ \\
\hline Frequency of measurement & Low & High & High \\
\hline Measurement standardization & Possible $^{\mathrm{a}}$ & Possible & Unnecessary \\
\hline Reproducibility & Unfavorable & Most favorable & Favorable \\
\hline White-coat phenomenon & Present & Absent & Absent \\
\hline Drug efficacy assessment & Possible & Optimal & Appropriate \\
\hline $\begin{array}{l}\text { Evaluation of the duration of drug } \\
\text { efficacy }\end{array}$ & Impossible & Most favorable & Possible \\
\hline $\begin{array}{l}\text { Evaluation of short-term variability } \\
\text { (variations at } 15 \text { - to } 30 \text {-min intervals) }\end{array}$ & Impossible & Impossible & Possible \\
\hline $\begin{array}{l}\text { Evaluation of diurnal changes } \\
\text { (evaluation of nocturnal blood pressure) }\end{array}$ & Impossible & Possible ${ }^{\mathrm{b}}$ & Possible \\
\hline Evaluation of day-by-day variability & Impossible & Possible & Impossible \\
\hline $\begin{array}{l}\text { Evaluation of long-term changes } \\
\text { (seasonal variation) }\end{array}$ & Possible & Most favorable & Possible \\
\hline
\end{tabular}

a Standardized measurement increases the clinical value of office blood pressure. In clinical practice, standardized measurement is often not performed. Standardized office blood pressure measurement is strongly recommended.

${ }^{\mathrm{b}}$ Home blood pressure-measuring devices that can monitor blood pressure during sleep at night are available. Reproduced from Umemura et al. [1]. blood pressure is widely prevalent in Japan, e.g., $77 \%$ of patients with hypertension and $40 \%$ of individuals possess a home blood pressure measurement device, and $~ 40$ million home blood pressure devices are estimated to be in use in Japan [1, 39]. A lot of Japanese routinely measure home blood pressure and therefore doctors, healthcare providers as well as people themselves have required the classification based on home blood pressure. Home blood pressure is further used as the prioritized diagnosis information of hypertension when an office blood pressure-based diagnosis differs [1]. To suit the clinical practice, it is reasonable that the JSH 2019 Guidelines differ from those from the other regions $[2,3]$. Similar to the relationship between conventional office and AOBP, home blood pressure is emphasized more than ambulatory blood pressure because ambulatory monitoring is expensive and certain mental/physical stresses in a person are invoked during the measurement [40], although the advantages of ambulatory measurement are stated in the JSH 2019 Guidelines [1].

As a successful example, an emerging topic first comes to fruition as specific guidelines, and is integrated to broad guidelines several years later. The initial guidelines for selfmeasured home blood pressure were published in Japan in 2003 [41] and revised in 2012 [42], and the unique utility of home blood pressure as the prioritized diagnostic tool was emphasized in the JSH 2014 [43], which continues to the most recent JSH 2019, as abovementioned [1]. Meanwhile, a joint policy statement on home blood pressure was recently published by the AHA and the American Medical Association [44]. In the statement [44], the advantages and recommended use of home blood pressure were described in detail. What should be noted by those outside the USA is that, although not applicable to all regions (states), a few private and commercial payers and the domestic insurance agencies (Medicaid and Medicare) have started to support self-measured home blood pressure monitoring since 2020. Pickering et al. [45], some of whom were also coauthors of the statement [44], called for action on home blood pressure measurement and emphasized the importance of reimbursement of the measurement. Ambivalent situations remain in Japan with respect to repeated petitions for reimbursement of home blood pressure measurement that have been declined by the government because the measurement is already in widespread use. We understand the severe financial situation; however, introducing the reimbursement shall enhance the support for home blood pressure measurement among people, particularly those with special needs, to improve the population health of society. Furthermore, our cost analysis revealed that the introduction of home blood pressure measurement for hypertension treatment would be a very effective method of reducing costs of hypertension treatment and treatment years for hypertension [46]. The US action of introducing reimbursement can be as a pioneering step for other countries, and we expect to expand the application in the near future.

The International Society of Hypertension (ISH) recently published the Hypertension Practice Guidelines (2020 ISH Guidelines) [4]. In contrast to developed countries, out-ofoffice blood pressure measurement "may not be feasible in low resource settings" [4]. Nevertheless, the 2020 ISH Guidelines also emphasize the importance of out-of-office blood pressure measurement for the accurate diagnosis of 
Table 3 Criteria for hypertension based on office, ambulatory, and home blood pressure measurement.

\begin{tabular}{ll}
\hline Measurement & $\begin{array}{l}\text { Systolic/diastolic blood } \\
\text { pressure, } \mathrm{mmHg}\end{array}$ \\
\hline $\begin{array}{l}\text { Office blood pressure } \\
\text { Ambulatory blood pressure }\end{array}$ & $\geq 140$ and/or $\geq 90$ \\
24-h average & $\geq 130$ and/or $\geq 80$ \\
$\begin{array}{l}\text { Daytime or awake average } \\
\text { Nighttime or asleep } \\
\text { average }\end{array}$ & $\geq 135$ and/or $\geq 85$ \\
Home blood pressure & $\geq 135$ and/or $\geq 85$ \\
\hline
\end{tabular}

The criteria were consistently used in the US (2017 ACC/AHA) [3], European (2018 ESC/ESH) [2], Japanese (JSH 2019) [1], and international (2020 ISH) [4] guidelines.

hypertension and for treatment decisions when the measurement would be possible and available [4]. The criteria are consistent with the aforementioned guidelines as shown in Table 3, and the usefulness of the combination of office and out-of-office blood pressure measurements to identify people with white-coat hypertension and those with masked hypertension is also stated in detail. The 2020 ISH Guidelines [4] therefore guarantee the application of out-of-office blood pressure, and call for action on every effort worldwide including out-of-office blood pressure measurement, somewhat like the previous US statement [44].

\section{Importance of accurate measurement of blood pressure for diagnosing and treating hypertension}

For diagnosing and treating hypertension, accurate blood pressure measurement as well as reliable data sources are essential. However, recently emerged reports in relation to coronavirus disease-2019 (COVID-19) have unveiled the current inconvenient situation. In our recent review on the association between hypertension and COVID-19 available as of June 7, 2020 [47], none of the nine available epidemiological studies concerning the association between hypertension and COVID-19 stated the diagnostic methodology used or the criteria for hypertension, such as inoffice or out-of-office blood pressure, or self-reported or testimony of a family in serious situations. The huge variation in data sources makes the evaluation of reported incidence and risk of hypertension inaccurate [47]. We must keep tackling appropriate assessment of blood pressure during peacetime, in usual daily routines, so that we can provide timely and accurate evidence on hypertension under any situation, including an unexpected pandemic.
Acknowledgements We gratefully acknowledge the clerical assistance of Rie Morioka, Sachiko Matsuda, and Masako Terui at the Department of Hygiene and Public Health, Teikyo University School of Medicine, Tokyo, and Hiromi Murakami at the Tohoku Institute for Management of Blood Pressure, Sendai, Japan.

\section{Compliance with ethical standards}

Conflict of interest The authors declare no competing interests.

Publisher's note Springer Nature remains neutral with regard to jurisdictional claims in published maps and institutional affiliations.

\section{References}

1. Umemura S, Arima H, Arima S, Asayama K, Dohi Y, Hirooka Y, et al. The Japanese Society of Hypertension Guidelines for the Management of Hypertension (JSH 2019). Hypertens Res. 2019;42:1235-481.

2. Williams B, Mancia G, Spiering W, Agabiti Rosei E, Azizi M, Burnier M, et al. ESC/ESH Guidelines for the management of arterial hypertension. Eur Heart J. 2018;2018:3021-104.

3. Whelton PK, Carey RM, Aronow WS, Casey DE Jr., Collins KJ, Dennison Himmelfarb C, et al. 2017 ACC/AHA/AAPA/ABC/ ACPM/AGS/APhA/ASH/ASPC/NMA/PCNA Guideline for the Prevention, Detection, Evaluation, and Management of High Blood Pressure in Adults: a report of the American College of Cardiology/American Heart Association Task Force on Clinical Practice Guidelines. Hypertension. 2018;71:e13-115.

4. Unger T, Borghi C, Charchar F, Khan NA, Poulter NR, Prabhakaran D, et al. International Society of Hypertension Global Hypertension Practice Guidelines. Hypertension. 2020;2020:1334-57.

5. Stergiou GS, Doumas M, Kollias A, Papademetriou V. Important practice lessons from the SPRINT study beyond the blood pressure goal: all well known and now confirmed. J Am Soc Hypertens. 2016;10:613-7.

6. Myers MG, Godwin M, Dawes M, Kiss A, Tobe SW, Grant FC, et al. Conventional versus automated measurement of blood pressure in primary care patients with systolic hypertension: randomised parallel design controlled trial. BMJ. 2011;342:d286.

7. Johnson KC, Whelton PK, Cushman WC, Cutler JA, Evans GW, Snyder JK, et al. Blood pressure measurement in SPRINT (Systolic Blood Pressure Intervention Trial). Hypertension. 2018;71:848-57.

8. Asayama K, Ohkubo T, Rakugi H, Miyakawa M, Mori H, Katsuya $\mathrm{T}$, et al. Comparison of blood pressure values-selfmeasured at home, measured at an unattended office, and measured at a conventional attended office. Hypertens Res. 2019;42:1726-37.

9. Etyang AO, Sigilai A, Odipo E, Oyando R, Ong'ayo G, Muthami $\mathrm{L}$, et al. Diagnostic accuracy of unattended automated office blood pressure measurement in screening for hypertension in Kenya: a population based study. Hypertension. 2019;74:1490-8.

10. Stults B, Doane J, Penrod MJ, Conroy MB. Does automated office blood pressure require a 5-minute rest period when used to screen for hypertension? J Clin Hypertens. 2018. https://doi.org/10.1111/ jch.13446.

11. Nerenberg KA, Zarnke KB, Leung AA, Dasgupta K, Butalia S, McBrien K, et al. Hypertension Canada's 2018 Guidelines for diagnosis, risk assessment, prevention, and treatment of hypertension in adults and children. Can J Cardiol. 2018;34:506-25. 
12. Myers MG, Colella TJF. Response to: does AOBP require a 5minute rest period to screen for hypertension? J Clin Hypertens. 2019;21:137.

13. Roerecke M, Kaczorowski J, Myers MG. Comparing automated office blood pressure readings with other methods of blood pressure measurement for identifying patients with possible hypertension: a systematic review and meta-analysis. JAMA Intern Med. 2019;179:351-62.

14. Asayama K, Ohkubo T. Unattended automated measurementsoffice and out-of-office blood pressure affected by medical staff and environment. Hypertension. 2019;74:1294-6.

15. Asayama K, Fujiwara T, Hoshide S, Ohkubo T, Kario K, Stergiou GS, et al. Nocturnal blood pressure measured by home devices: evidence and perspective for clinical application. J Hypertens. 2019;37:905-16.

16. Yang WY, Melgarejo JD, Thijs L, Zhang ZY, Boggia J, Wei FF, et al. Association of office and ambulatory blood pressure with mortality and cardiovascular outcomes. JAMA. 2019;322: 409-20.

17. Asayama K, Ohkubo T, Metoki H, Obara T, Inoue R, Kikuya M, et al. Cardiovascular outcomes in the first trial of antihypertensive therapy guided by self-measured home blood pressure. Hypertens Res. 2012;35:1102-10.

18. Ohkubo T, Imai Y, Tsuji I, Nagai K, Kato J, Kikuchi N, et al. Home blood pressure measurement has a stronger predictive power for mortality than does screening blood pressure measurement: a population-based observation in Ohasama, Japan. J Hypertens. 1998;16:971-5.

19. Asayama K, Thijs L, Brguljan-Hitij J, Niiranen TJ, Hozawa A, Boggia J, et al. Risk stratification by self-measured home blood pressure across categories of conventional blood pressure: a participant-level meta-analysis. PLoS Med. 2014;11:e1001591.

20. Brguljan-Hitij J, Thijs L, Li Y, Hansen TW, Boggia J, Liu YP, et al. Risk stratification by ambulatory blood pressure monitoring across JNC classes of conventional blood pressure. Am J Hypertens. 2014;27:956-65.

21. Satoh M, Asayama K, Kikuya M, Inoue R, Metoki H, Hosaka M, et al. Long-term stroke risk due to partial white-coat or masked hypertension based on home and ambulatory blood pressure measurements: the Ohasama study. Hypertension. 2016;67:48-55.

22. Asayama K, Tabara Y, Oishi E, Sakata S, Hisamatsu T, Godai K, et al. Recent status of self-measured home blood pressure in the Japanese general population: a modern database on self-measured home blood pressure (MDAS). Hypertens Res. 2020;43:1403-12.

23. Asayama K, Ohkubo T, Hoshide S, Kario K, Ohya Y, Rakugi H, et al. From mercury sphygmomanometer to electric device on blood pressure measurement: correspondence of Minamata Convention on Mercury. Hypertens Res. 2016;39:179-82.

24. Godai K, Kabayama M, Saito K, Asayama K, Yamamoto K, Sugimoto K, et al. Validation of an automated home blood pressure measurement device in oldest-old populations. Hypertens Res. 2020;43:30-5.

25. International Organization for Standardization. ISO 810602:2013, non-invasive sphygmomanometers-part 2: clinical investigation of automated measurement type. 2013. https://www. iso.org/standard/57977.html. Accessed 2 Apr 2020.

26. Stergiou GS, Alpert B, Mieke S, Asmar R, Atkins N, Eckert S, et al. A universal standard for the validation of blood pressure measuring devices: Association for the Advancement of Medical Instrumentation/European Society of Hypertension/International Organization for Standardization (AAMI/ESH/ISO) Collaboration Statement. Hypertension. 2018;71:368-74.

27. International Organization for Standardization. ISO 810602:2018, Non-invasive sphygmomanometers-part 2: clinical investigation of automated measurement type. 2018. https://www. iso.org/standard/73339.html. Accessed 15 Dec 2018.
28. Association for the Advancement of Medical Instrumentation, American National Standards Institute, International Organization for Standardization. AAMI/ANSI/ISO 81060-2:2013, noninvasive sphygmomanometers-part 2: clinical investigation of automated measurement type. 2013. http://my.aami.org/aa miresources/previewfiles/8106002_1306_preview.pdf. Accessed 26 Sept 2017.

29. Sharman JE, Padwal R, Campbell NRC. Global marketing and sale of accurate cuff blood pressure measurement devices. Circulation. 2020;142:321-3.

30. Picone DS, Deshpande RA, Schultz MG, Fonseca R, Campbell NRC, Delles C, et al. Nonvalidated home blood pressure devices dominate the online marketplace in Australia: major implications for cardiovascular risk management. Hypertension. 2020;75:1593-9.

31. Padwal R, Campbell NRC, Weber MA, Lackland D, Shimbo D, Zhang XH, et al. The Accuracy in Measurement of Blood Pressure (AIM-BP) collaborative: background and rationale. J Clin Hypertens. 2019;21:1780-3.

32. Sharman JE, O'Brien E, Alpert B, Schutte AE, Delles C, Hecht Olsen M, et al. Lancet Commission on Hypertension group position statement on the global improvement of accuracy standards for devices that measure blood pressure. J Hypertens. 2020;38:21-9.

33. Campbell NR, Gelfer M, Stergiou GS, Alpert BS, Myers MG, Rakotz MK, et al. A call to regulate manufacture and marketing of blood pressure devices and cuffs: a position statement from the World Hypertension League, International Society of Hypertension and Supporting Hypertension Organizations. J Clin Hypertens. 2016;18:378-80.

34. dabl ${ }^{\circledR}$ Educational Trust Limited. dabl Educational Trust 2004. http://dableducational.org/. Accessed 10 Sept 2020.

35. Medaval Limited. Medaval. 2015. http://medaval.org/. Accessed 10 Sept 2020.

36. Stergiou GS, O’Brien E, Myers M, Palatini P, Parati G, STRIDE BP Scientific Advisory Board. STRIDE BP: an international initiative for accurate blood pressure measurement. J Hypertens. 2020;38:395-9.

37. Jones DW. Response to implementing automated office blood pressure measurement: controversies in hypertension-con side of the argument. Hypertension. 2019;74:449.

38. Niiranen TJ, Asayama K, Thijs L, Johansson JK, Ohkubo T, Kikuya $\mathrm{M}$, et al. Outcome-driven thresholds for home blood pressure measurement: international database of home blood pressure in relation to cardiovascular outcome. Hypertension. 2013;61:27-34.

39. Shirasaki O, Terada H, Niwano $K$, Nakanishi T, Kanai $M$, Miyawaki Y, et al. The Japan Home-health Apparatus Industrial Association: investigation of home-use electronic sphygmomanometers. Blood Press Monit. 2001;6:303-7.

40. Kobayashi K, Sato K, Hatori N, Miyakawa M. A questionnaire survey of general practitioners in Japan's Kanagawa Prefecture for the Japanese Society of Hypertension Guidelines for the Management of Hypertension 2014. Clin Exp Hypertens. 2017;39:705-10.

41. Imai Y, Otsuka K, Kawano Y, Shimada K, Hayashi H, Tochikubo $\mathrm{O}$, et al. Japanese Society of Hypertension (JSH) guidelines for self-monitoring of blood pressure at home. Hypertens Res. 2003;26:771-82.

42. Imai Y, Kario K, Shimada K, Kawano Y, Hasebe N, Matsuura H, et al. The Japanese Society of Hypertension guidelines for selfmonitoring of blood pressure at home (second edition). Hypertens Res. 2012;35:777-95.

43. Shimamoto K, Ando K, Fujita T, Hasebe N, Higaki J, Horiuchi M, et al. The Japanese Society of Hypertension Guidelines for the Management of Hypertension (JSH 2014). Hypertens Res. 2014;37:253-390. 
44. Shimbo D, Artinian NT, Basile JN, Krakoff LR, Margolis KL, Rakotz MK, et al. Self-Measured Blood Pressure Monitoring at Home: a joint policy statement from the American Heart Association and American Medical Association. Circulation. 2020;142:e42-63.

45. Pickering TG, Miller NH, Ogedegbe G, Krakoff LR, Artinian NT, Goff D. Call to action on use and reimbursement for home blood pressure monitoring: a joint scientific statement from the American Heart Association, American Society of Hypertension, and Preventive Cardiovascular Nurses Association. Hypertension. 2008;52:10-29.
46. Fukunaga H, Ohkubo T, Kobayashi M, Tamaki Y, Kikuya M, Obara T, et al. Cost-effectiveness of the introduction of home blood pressure measurement in patients with office hypertension. J Hypertens. 2008;26:685-90.

47. Shibata S, Arima H, Asayama K, Hoshide S, Ichihara A, Ishimitsu $\mathrm{T}$, et al. Hypertension and related diseases in the era of COVID-19: a report from the Japanese Society of Hypertension Task Force on COVID-19. Hypertens Res. 2020;43:1028-46. 